\title{
La usanza del título valor "cheque" por parte de la administración pública según la legislación mercantil vigente
}

\author{
The use of the Bank checks by \\ the administration according to \\ current commercial law
}

María Cristina Arrieta BlanquicetT**

\section{RESUMEN}

El presente estudio, analiza la problemática derivada de la tensión entre las normas mercantiles y la prolija regulación inherente a la protección del patrimonio público, surgidas por el giro de cheques de la administración.

Palabras claves: Cheque, bien mercantil, comerciante, principios de los títulos valores, contratación estatal reglada, legalidad del gasto público.

\section{ABSTRACT}

The present study analyzes the problems derived from the tension between commercial law and the regulation inherent in the protection of public assets, arising from the administration's checks.

* Fecha de recepción: 25 de agosto de 2019. Fecha de aceptación: 12 de diciembre de 2019. Para citar el artículo: Arrieta M. "La usanza del título valor "cheque" por parte de la administración pública según la legislación mercantil vigente". En Revist@ E-Mercatoria, vol. 18, n. ${ }^{\circ}$ 2, julio-diciembre, 2019. DOI: https://doi.org/10.18601/16923960.v18n2.04

** Abogada egresada de la Universidad del Cauca, especialista en derecho contractual y relaciones jurídico negociales, Magister en derecho comercial de la Universidad Externado de Colombia, docente de posgrado de la Corporación Universitaria del Caribe CecarColombia-cristi197629@gmail.com. 
Key words: Check, mercantile good, merchant, principles of securities, regulated state contracting, legality of public spending.

\section{INTRODUCCION}

Los títulos valores en Colombia se encuentran consagrados en el libro III título III capítulo I, del decreto 410 del 27 de marzo de 1971 (Código de Comercio), "De los Bienes Mercantiles", y en el capítulo V sección III subsección I, se encuentran estipuladas las normas sobre el cheque.

La Ley $1^{a}$ de 1980 adicionó, el libro 3o., título III, capítulo V del Código de Comercio en la subsección de los cheques especiales, consagrando el "cheque fiscal", como un avance significativo que consideró el especial uso que se debía dar a este bien mercantil, cuando el título valor fuera girado a nombre de una entidad pública.

Con posterioridad, y con la expedición de la Ley 80 de 1993 se erige por primera vez en Colombia el estatuto de contratación estatal, el cual sometió la contratación pública a una serie de formalidades "Función reglada"1.

Así las cosas, la ley 80 de 1993, en su artículo $13^{\circ}$ dispuso que: "Los contratos estatales, es decir, aquellos que celebren las entidades estatales, les serán aplicables las normas civiles y comerciales en lo que no esté regulado por ella"2.

A pesar de lo anterior, en la actualidad, las normas relativas a los títulos valores no han sufrido reformas sustanciales de gran amplitud, muy a pesar del advenimiento del estado social de derecho que introdujo la constitución política de 1991, el auge de la tecnología, el comercio electrónico, la globalización, los contratos informáticos y telemáticos y el incremento de la contratación masificada y a distancia.

En tal virtud, no se puede desconocer que, en algunos aspectos, la legislación civil y comercial se caracteriza por su obsolescencia, y en lo que se refiere a los títulos valores "cheque", tampoco escapan de una legislación que no evolucionó al ritmo de las realidades sociales, del estado social de derecho y los principios de la contratación pública.

Dentro de este contexto, es importante identificar que la legislación colombiana se compone de un sin número de normas que funcionan dentro de un engranaje formando un "sistema de normas", razones por las que estas

1 Sentencia c-154 de 1997 "Lo que significa que debe someterse estrictamente a las estipulaciones legales sobre el particular".

2 Artículo 13. De la normatividad aplicable a los contratos estatales. Los contratos que celebren las entidades a que se refiere el artículo 2o. del presente estatuto se regirán por las disposiciones comerciales y civiles pertinentes, salvo en las materias particularmente reguladas en esta ley. 
deben ser interpretadas de forma sistemática y no aislada, tomando en consideración la finalidad de cada norma y buscando siempre el interés general.

A partir de la Constitución Política de 1991, se requiere que todas las normas que se expidieron con anterioridad a esta, sean filtradas a la luz de los principios y valores allí establecidos.

Así las cosas, el Código de Comercio colombiano (Decreto 410 de 1971), norma que consagra el régimen de los títulos valores, parte de la premisa que existe un acto mercantil al momento de girar un "cheque". Sin embargo; para la fecha de expedición de la citada norma, no se contempló su uso por parte de la administración pública.

Aunado a lo anterior, en el Código de Comercio colombiano, los títulos valores son catalogados como "bienes mercantiles". Razones por las que hasta el momento nada se plantea sobre la necesidad que tienen las entidades estatales sobre el uso del cheque y sus límites.

Como corolario de lo anterior, con otra óptica urge analizar este tipo de actos que realiza la administración pública, obligando a la jurisprudencia y doctrina a considerar si su actuación es o no, un verdadero acto de comercio; ya que la aplicación del código de comercio es exclusiva para "Los comerciantes $y$ los asuntos mercantiles".

Aunado a lo anterior, se requiere analizar si los principios de los títulos valores, tales como: Autonomía y circulación deben prevalecer frente a principios constitucionales como la legalidad del gasto público y la contratación estatal reglada.

Los interrogantes aquí planteados se desprenden de una investigación con fines académicos, así como de la experiencia de la autora.

Para dar respuesta a los anteriores interrogantes, se desarrollarán los siguientes:

\section{EL CHEQUE EN LA LEGISLACION COLOMBIANA}

\section{ANTECEDENTES LEGISLATIVOS DEL CHEQUE}

La primera norma que se expidió en Colombia en relación al cheque fue la Ley 75 de diciembre de 1916, mediante la cual se reglamentó su uso; luego, con la expedición de la Ley 46 de 1923, ley que se refirió a los instrumentos negociables, reconociendo al cheque como uno de los principales instrumentos.

El artículo artículo $3^{\circ}$ de la citada ley, desde ese entonces, consagró lo siguiente: "Los bonos, obligaciones o cupones de deuda, emitidos por entidades públicas o privadas, serán negociables de acuerdo con el contrato en que se baya fundado la emisión de ellos, y a falta de tal disposición, de acuerdo con las prescripciones legales pertinentes (...)". 
Por lo anterior, la citada norma desde el año 1923, ya preveía como las entidades públicas podían utilizar instrumentos negóciales, siempre y cuando preexistiera un contrato que le diera origen al mismo, y a pesar que el estatuto de contratación estatal aún no existía, el legislador tuvo claridad acerca de la subordinación de dichos instrumentos, a la especial forma de contratación del Estado.

Posteriormente, el decreto 410 del 27 de marzo de 1971, actual Código de Comercio colombiano, consagró en el capítulo V sección III subsección I, las normas sobre el cheque, las cuales quedaron contempladas en los artículos 712 a 751.

Dentro de la legislación antes citada se puede inferir algunas especificidades acerca del citado título valor tales como: Su vencimiento a la vista, la necesidad de provisión de fondos, la prescripción de la acción cambiaria en 6 meses, requiere el protesto para el pago, entre otras especificidades.

Luego, la Ley $1^{\circ}$ de 1980, creó el cheque fiscal, definiendo como tales a aquellos que son girados a favor de entidades públicas; vale decir, que dicha norma adicionó el código de comercio, e hizo la salvedad sobre esta especialidad de cheque, consagrando algunas limitantes respecto al uso y circulación del mismo.

En virtud de la citada ley, el artículo $3^{\circ}$ consagró unas talanqueras para la creación de cuentas corrientes cuando se trate de entidades públicas, remitiendo la norma a los requisitos y/o reglamentos que establezcan las entidades fiscalizadoras para su efecto; razones por las que se puede concluir que el legislador siempre ha tenido su visión despejada sobre la utilización del cheque en el sector público, el cual ${ }_{i}$ en algunos aspectos no podrá asimilarse al uso que se le da en el sector privado.

\section{El USO DEL CHEQUE EN EL AMBito DEL DERECHO PúBliCO EN COLOMBIA}

La Corte Constitucional en sentencia de constitucionalidad C-451 de 2002, fue enfática en reiterar que los títulos valores generan derechos distintos a los propios de la relación contractual que dio origen y que estos dan seguridad jurídica al acreedor.

Ahora bien, en lo pertinente al cheque, también señaló: "La seguridad jurídica cobra una importancia particular al tratarse del cheque, no sólo por la cantidad de cheques que se emiten y circulan diariamente, en comparación con otros títulos valores, sino porque, al ser un instrumento de pago, que sirve de reemplazo al dinero en efectivo, es de uso generalizado en ámbitos que rebasan el del gremio de comerciantes".

Como corolario de lo anterior, la misma Corte Constitucional muy a pesar que reconoce el principio de autonomía de los títulos valores, resalta a la vez, que el uso del cheque se ha masificado de tal manera, que se ha extendido aún entre los no comerciantes. 
La anterior afirmación enfila un punto de partida en esta reflexión académica, y es que a pesar que no cabe duda que el cheque es un bien mercantil, y que no se desconocen sus principios como título valor; su uso se da entre diversas personas ya sea: naturales, jurídicas, comerciantes, no comerciantes y aún por entidades del Estado; y para este último caso, es preciso legislar, en aras de preservar el patrimonio público ${ }^{4}$.

De conformidad con lo antes mencionado, y descendiendo a la discusión central se puede puntualizar en que a diferencia de la época en la que se legisló sobre el cheque, hoy resulta muy usual este medio de pago en la administración pública en Colombia. Sin embargo; la legislación existente no alcanza a comprender un sinnúmero de situaciones concretas que pueden surgir en su dinámica y que pueden generar tensión respecto a sus principios.

En relación a los principios de los títulos valores en general, el artículo 619 del Código de Comercio señala que: "Los títulos-valores son documentos necesarios para legitimar el ejercicio del derecho literal y autónomo que en ellos se incorpora";

De la anterior definición se infieren los siguientes principios: incorporación, legitimación, literalidad, autonomía, circulación. Sin embargo, en lo que se refiere al tema que nos ocupa, la tensión fundamentalmente se haya en algunos de los principios, tales como: la autonomía y circulación del cheque, frente a principios que operan en la administración pública, como el de legalidad del gasto público y contratación estatal reglada:

Por lo anterior, primigeniamente se debe hacer claridad en que frente al principio de la autonomía, la doctrina ha señalado que consiste en: "Una figura que le es inberente a los títulos valores"

Así mismo, se dice que: "La autonomía está ligada al concepto que de circulación existe para que adquirentes sucesivos del título, tengan una posición inexpugnable, en aras de salvaguardar la seguridad y celeridad en el tráfico mercantil, contaran con la tranquilidad de que negocios en los que no intervinieron no pueden afectarlos".

4 El concepto atañe a la ciencia de la administración pública y es fundamental en el campo del derecho público administrativo. De una parte constituye objeto de gestión y por el otro objeto de preservación para evitar atentados contra el mismo, remediar situaciones creadas, o intervenir judicialmente para su restauración o recomposición. "Del patrimonio público una aproximación al concepto y a su contenido. Jesús MARÍA CARRILLO BALLESTEROS, revista Prolegómenos de la Universidad Militar de la Nueva Granada, volumen 9, número 17, enero- junio 2006, pp. 23-24. ISSN 0121-182X

5 ROMÁN GUIO FOnSECA MARCOS, Los títulos valores, análisis jurisprudencial, ediciones doctrina y ley, p. 48.

6 ROMÁn Guio FOnSECA MARCOS, Los títulos valores, análisis jurisprudencial, ediciones doctrina y ley, p. 48. 
En relación al principio de circulación, se ha dicho que: "Es la puesta en marcha del título valor bacia tenedores distintos del tomador o beneficiario de acuerdo con la ley que le baya impuesto su creador"7.

La posible tensión, entre principios de derecho mercantil (Títulos valores), con el derecho público; se sostiene sobre el siguiente fundamento normativo, así:

1. Según las voces del artículo 641 del Código de Comercio, el cual dispone que los representantes legales están autorizados para suscribir títulos valores a nombre de la entidad que representan así:

"Los representantes legales de sociedades y los factores se reputarán autorizados, por el solo becho de su nombramiento, para suscribir títulos-valores a nombre de las entidades que administren".

Sin embargo, al descender a las normas especiales de la administración pública, otra es la óptica con la que se debe analizar dicha norma, ya que los representantes de las diversas modalidades de entidades, antes de suscribir un título valor, deben someterse a principios constitucionales y legales que los obligan a cumplir los fines de la función administrativa, sujetándose por tanto al hecho que todo gasto público ${ }^{8}$ parte del principio de legalidad.

En sentencia de constitucionalidad C-772 de 1998, la Corte constitucional hizo referencia a la naturaleza jurídica de este principio así:

"Uno de esos principios es el de legalidad, el cual se constituye en uno de los fundamentos más importantes de las democracias constitucionales. "Según tal principio, corresponde al Congreso, como órgano de representación plural, decretar y autorizar los gastos del Estado, pues ello se considera un mecanismo necesario de control al Ejecutivo y una expresión inevitable del principio democrático y de la forma republicana de gobierno. En el constitucionalismo colombiano, la legalidad del gasto opera en dos momentos diferenciados, pues en general las erogaciones no sólo deben ser previamente decretadas por la ley sino que, además deben ser apropiadas por la Ley de presupuesto para poder ser efectivamente realizadas".

En este orden de ideas, es claro que, en la administración pública, muy a pesar de las prerrogativas establecidas en el artículo 641 del Código de Comercio, el

7 ROMÁN GUIO FOnSECA MARCOS, Los títulos valores, análisis jurisprudencial, ediciones doctrina y ley, p. 48.

8 La ciencia de la administración pública precisa también la necesidad del conocimiento de todo cuanto pertenece al Estado y es de su interés, para efectuar una gestión eficaz, para que se genere nueva riqueza, y se incremente el patrimonio público mejorándolo en todos sus aspectos, con lo cual llegue hasta el último de los asociados que si bien no son sus titulares directos, son sus reales beneficiarios. Dicho de otra manera, el conocimiento del patrimonio público, de su composición, de su destino y de su defensa, es un fundamento para combatir la corrupción que flagela buena parte de los Estados contemporáneos y especialmente los más pobres. 
límite para la suscripción de un título valor que genere obligaciones a cargo de la entidad que representa, es que dicho gasto parta del principio de legalidad.

\section{EL USO DEL CHEQUE EN LA CONTRATACIÓN PÚBLICA}

De conformidad con el recuento anterior, se ha venido insistiendo en el uso frecuente por parte de la administración pública de algunos bienes mercantiles, tales como los títulos valores, y en especial el cheque; motivación para que en este estudio se comprenda que existen actuaciones de la administración pública que pueden estar sujetas al derecho privado, o por lo menos; en donde su actuar se asemeja al de un particular, así:

"( (...)

-Actos de provisión

-Actividad empresarial

-Ejercicio de algunas funciones administrativas a través de empresas privadas". ${ }^{\prime \prime}$

En el escenario anterior, es donde se pueden presentar algunas circunstancias que generan tensión referente a la principialistica antes citada, por lo que se analizará la doble forma de utilización de cheques por parte de la administración, ya sea en calidad de legitimado por pasiva o activa.

1. Legitimación por pasiva: La Ley $1^{\circ}$ de 1980 , creó el cheque fiscal, definiendo como tales a aquellos que son girados a favor de entidades públicas; vale decir, que dicha norma adicionó el código de comercio, e hizo la salvedad sobre esta especialidad de cheque, consagrando algunas limitantes respecto al uso y circulación del mismo así:

"Artículo 10. Adicionase el Libro 30, Título III, Capítulo V, Sección 3, Subsección 3, del Código de Comercio, con los siguientes artículos: Artículo $1^{\circ}$. Denominense Cheques Fiscales aquellos que son girados por cualquier concepto a favor de las entidades públicas definidas en el artículo 20 del Decreto 130 de 1976. Los Cheques Fiscales creados por la presente Ley tienen las siguientes características:

1․ El beneficiario sólo podrá ser la entidad pública a la cual se baga el respectivo pago.

$2^{\circ}$. No podrán ser abonados en cuenta diferente a la de la entidad pública beneficiaria.

30. No podrán modificarse al reverso la forma de negociación ni las condiciones de los mismos establecidos en el artículo 713 del Código de Comercio.

9 Administración pública y derecho administrativo, p. 41, biblioteca jurídica virtual del instituto de investigaciones jurídicas de la UNAM. www. Juridicas.unam.mx 
$4^{\circ}$. No son negociables ni podrán ser pagados en efectivo.

A estos Cheques se aplicarán en lo pertinente las normas contenidas en los artículos 737 y 738 del Código de Comercio.

Parágrafo. Probíbase a las entidades sometidas al control y vigilancia de la Superintendencia Bancaria acreditar o abonar en cuentas particulares cheques girados a nombre de las entidades públicas".

De lo anterior, vale la pena rescatar que, en estos eventos específicos, donde la administración es la beneficiaria del título valor (Cheque), si existe legislación al respecto, y son pacíficas las restricciones legales en su uso, en aras de proteger el patrimonio público; prohibiéndose su circulación y haciéndolo innegociable. Situación que tal y como se dijo en líneas anteriores, contraría principios de derecho mercantil (títulos valores), como la circulación y por ende su autonomía.

Se concluye entonces que el legislador a través de la ley $1^{\circ}$ de 1980 , la cual reformó el Código de Comercio; tuvo previsión sobre la disyuntiva aquí planteada, por lo que se anticipó a tomar medidas legislativas afirmativas, para cumplir los fines del Estado, pero únicamente cuando este se encuentra legitimado por pasiva.

2. Legitimación por activa: frente a este otro extremo en que puede actuar la administración, es distinta la situación, siendo esta confusa y caótica, pues al no existir legislación respecto, la tarea le corresponde a las altas Cortes, en el sentido de crear jurisprudencia cuando existe cuestión litigiosa respecto a su ejecución cuando estos son la base del recaudo; así mismo, es a los jueces de la República a quienes les corresponde aplicar el derecho existente ${ }^{10} \mathrm{y} / \mathrm{o}$ la jurisprudencia al caso concreto.

Bajo esta óptica es importante comparar como la naturaleza jurídica del cheque fiscal, es distinta a la naturaleza de los títulos valores emitidos por la administración, ya que estos últimos su naturaleza es eminentemente mercantil, y según dicha legislación; gozan de autonomía y libre circulación, siendo entonces poca la herramienta jurídica con la que se dota al juez ordinario en su especialidad civil; cuando se inicia una ejecución contra la administración, cuando se tiene como base del recaudo, un título valor y en especial (un cheque), ya que no puede declarar la prescripción de la acción cambiaria de oficio, ni puede exigir la existencia de un certificado de disponibilidad presupuestal, o registro presupuestal, tampoco puede exigir más documentación, debido a que la tesis imperante en la actualidad es que no se requiere ni se trata de "títulos complejos". 
Cabe destacar que la ley $1^{\circ}$ de 1980 en el artículo $3^{\circ}$, también dispuso:

"Artículo $3^{\circ}$. Las únicas personas autorizadas para celebrar contratos de cuenta corriente bancaria a nombre de las entidades públicas son su representante legal o Jefe de la entidad respectiva y en su defecto las personas en quienes éstos deleguen, previo visto bueno de la Tesorería General de la República o las Tesorerías Departamentales o Municipales según el caso. Las cuentas corrientes bancarias de las entidades públicas deberán ser abiertas y mantenidas con el lleno de los requisitos legales y reglamentarios establecidos o que establezcan las autoridades fiscalizadoras del orden nacional, departamental o municipal, en forma tal, que ningún establecimiento bancario podrá abrir cuenta alguna sin el previo cumplimiento de tales requisitos".

Siendo esta una de las muchas normas en donde se imponen requisitos previos a la suscripción del cheque por parte de la administración, sin embargo; el objeto central de este estudio recae en la ausencia de legislación cuando ya es emitido el respectivo título y su posterior negociación con posible menoscabo del patrimonio público.

\section{La contratacion estatal desde la Constitucion Política de 1991}

La Corte Constitucional mucho ha ilustrado sobre la contratación estatal en el estado social de derecho, así como sus fines; primando siempre el interés general así:

"El fin de la contratación pública en el Estado Social de Derecho está directamente asociado al cumplimiento del interés general, puesto que el contrato público es uno de aquellos "instrumentos jurídicos de los que se vale el Estado para cumplir sus finalidades, bacer efectivos los deberes públicos y prestar los servicios a su cargo, con la colaboración de los particulares a quienes corresponde ejecutar, a nombre de la administración, las tareas acordadas. El interés general, además de guiar y explicar la manera como el legislador está llamado a regular el régimen de contratación administrativa, determina las actuaciones de la Administración, de los servidores que la representan y de los contratistas, estos últimos vinculados al cumplimiento de las obligaciones generales de todo contrato y por ende supeditados al cumplimiento de los fines del Estado"11.

Por ende, con la Constitución de 1991 la contratación estatal en Colombia, adquiere una raigambre constitucional, debido a los principios y valores allí enmarcados; especialmente en el preámbulo y los artículos $1^{\circ}$ y $2^{\circ}$, por lo que se requiere interpretar sus normas de forma sistemática y atendiendo los fines del Estado social de derecho.

De acuerdo al planteamiento del problema central en la utilización del cheque por parte de la administración pública, pueden surgir diversas situaciones que conllevan a generar tensión entre principios de derecho mercantil (Títulos 
valores), y principios básicos de la administración pública, se requieren traer a colación una aproximación a su concepto, para una mayor comprensión de esta problemática.

-Contratación estatal reglada: El Consejo de Estado en su sala de consulta y servicio civil ha dicho que:

"La administración para seleccionar la oferta más favorable para sus intereses, contrario a lo que ocurre en el derecho común en el que prima la autonomía de la voluntad y la libertad de formas, está sujeta a los procedimientos preestablecidos en las leyes y reglamentos, lo que significa que en el derecho público la preparación, adjudicación y perfeccionamiento de los contratos del Estado es una actividad eminentemente reglada, de manera que las partes están en la obligación de cumplir con el procedimiento fijado por el orden jurídico, bajo la estricta observancia de los principios que garantizan el derecho a la igualdad y libre concurrencia de los oferentes y el cumplimiento de los fines estatales perseguidos con esta actividad. Las actuaciones administrativas contractuales están sujetas al principio de legalidad previsto en los artículos $6^{\circ}$ y 121 Constitución Política como postulado esencial del Estado Social de Derecho y de toda manifestación del poder público, conforme al cual, es legítima la actuación de las autoridades en cuanto se desarrolle dentro del preciso ámbito funcional definido por el legislador, proscribiendo las actuaciones de los servidores públicos que impliquen omisión o extralimitación en el ejercicio de las mismas; a la observancia del debido proceso, y a los principios de la función administrativa, desarrollados legalmente por el mismo Estatuto General de Contratación de la Administración Pública"12.

De acuerdo a lo anterior, se tiene que todos los actos de provisión para la administración, están sujetos a unos procedimientos preestablecidos; por lo que no le es dable al representante de la entidad pública generarle obligaciones a dicha entidad, de forma indiscriminada, siendo esta práctica común en algunas zonas del país en donde es poco o nulo el control estatal, por ser zonas de difícil acceso.

De modo tal que impera legislar sobre las restricciones de negociación de un título valor (Cheque), que se suscribe por el representante de una entidad pública sin que lo anteceda ningún contrato estatal, ni acto administrativo, ni ninguna otra fuente obligacional. En la actualidad, si bien existen leyes de derecho sancionatorio para este (En materia penal, fiscal, disciplinaria y otros) ; no es menos cierto que luego de librado el cheque, si este es negociado, no es posible hacerle exigencias distintas; y en el evento en que se hubiera extralimitado el emisor en cuanto a la disponibilidad y registro presupuestal o destinación específica de recursos; tampoco estas excepciones serian viable proponerlas, dejando a salvo el derecho del tenedor del título. Situación

12 Consejero ponente: Enrique Jose Arboleda Perdomo Bogotá, D.C., veinte (20) de mayo de dos mil diez (2010) Radicación n. ${ }^{\circ}$ 11001-03-06-000-2010-00034-00(1992) 
por la que es de mucha valía que cuando se pretenda ejecutar, se obligue al ejecutante, integrar el título complejo ${ }^{13}$.

El tratadista Mauricio Fernando Rodríguez Tamayo, en su obra La acción ejecutiva ante la jurisdicción administrativa, $5^{\text {a }}$ edición pagina 120 señala que: "(...) Pues tratándose, como se trata, de un título valor en el que interviene un ente territorial, dicho título es de los denominados títulos complejos, dada su naturaleza de origen y creación. Así la regla general en materia de ejecución contra entidades estatales, es la presencia de un título complejo".

Como corolario de lo anterior, la cita antes transcrita parte de la base que todo título valor tiene una fuente (En documentos) que sirven para constituir un título complejo, ya que la causa jurídica inicial de los títulos valores que emanan de la administración, será siempre un contrato estatal, para garantizar el cumplimiento de obligaciones contractuales.

Con la anterior tesis, no se pretende desconocer ni la naturaleza jurídica ${ }^{14}$, ni las características de los títulos valores, en especial su autonomía ${ }^{15}$ y libre circulación, ya que estos atributos se imponen para fomentar la transmisibilidad del documento. Sin embargo, al colisionar con los principios antes citados, se deja desprovista a la administración de mecanismos para la protección de sus recursos.

-Legalidad del gasto público: Este principio está definido en la Constitución Política en el artículo 345.

"En tiempo de paz no se podrá percibir contribución o impuesto que no figure en el presupuesto de rentas, ni bacer erogación con cargo al Tesoro que no se balle incluida en el de gastos. Tampoco podrá bacerse ningún gasto público que no baya sido decretado por el Congreso, por las asambleas departamentales, o por los concejos distritales o municipales, ni transferir crédito alguno a objeto no previsto en el respectivo presupuesto" 16

Con la anterior definición se despeja el camino que inicia su recorrido hasta la producción de un título valor, pero muy a pesar de esto, la praxis es distinta; siendo una realidad la cuestión litigiosa sobre casos de extralimitación de empleados públicos que han generado detrimento patrimonial respecto al uso indebido de dichos títulos valores, o por la ausencia de registro ${ }^{17} \mathrm{y}$ disponibilidad presupuestal.

13 Este planteamiento no es de recibo por algunos Tribunales Superiores de Distrito judicial del País, como el de Cartagena, sala civil.

14 Bienes mercantiles- Libro Tercero del Código de comercio.

15 artículo 627 del Código de comercio.

16 Negrilla y resaltado de la autora.

17 "El artículo 71 del Decreto 111 de 1996 establece que el registro presupuestal será un requisito de perfeccionamiento de actos administrativos $\mathrm{y}$, como es sabido, el contrato estatal no es un acto administrativo sino una figura jurídica distinta. El contrato es un acto bilateral mientras que el acto administrativo es una declaración unilateral de la voluntad de 


\section{La Sección Tercera del Consejo de Estado frente a este último tópico} sostuvo que:

"La sanción que se obtiene por no expedir el registro presupuestal no afecta al acto o al contrato sino a la persona que incumple con dicha obligación. Por eso el inciso final del artículo 71 del Decreto 111 de 1996 establece que "cualquier compromiso que se adquiera con violación de estos preceptos creará responsabilidad personal y pecuniaria a cargo de quien asuma estas obligaciones". De tal forma se evidencia que la omisión de expedir el registro presupuestal no se sanciona con la nulidad sino que el funcionario público competente responderá desde el ámbito disciplinario, penal. fiscal y patrimonial" 18 .

Conforme a la anterior cita, habría una responsabilidad patrimonial exclusiva para el funcionario público; sin embargo, nada se dice respecto al inminente e irremediable perjuicio para el patrimonio público y como impedir que este se produzca, por lo que no se cuenta con medidas legislativas afirmativas para la protección del patrimonio público de forma anticipada, pues de la cita antes expuesta, se deduce que debe iniciarse un juicio penal, fiscal y civil frente al presunto infractor, para que el Estado logre restablecer su patrimonio.

la administración. Por lo tanto, no se puede sostener que el artículo 71 del Decreto 111 de 1996 modificó el artículo 41 de la Ley 80 de 1993, pues éste aplica para los actos administrativos pero no para los contratos estatales". Observatorio colombiano de contratación pública. http://occp.co. Consejo de Estado Sala de lo Contencioso Administrativo Sección Tercera Subsección C Consejero ponente: Enrique Gil Botero Bogotá D.C., doce (12) de agosto de dos mil catorce (2014) Radicación n. ${ }^{\circ}$ 05001-23-31-000-1998-01350-01(28565).

18 Ley orgánica de presupuesto-Consagra una sanción, que no es la nulidad de los actos o contratos, cuando se compromete al Estado sin contar con registro presupuestal En los términos del art. 71 del Decreto 111 de 1996, cuando se exige registro presupuestal y la entidad no lo obtiene, la sanción que se aplica no afecta al acto o al contrato sino a la persona que incumple la obligación. Dispone el inciso final de dicha norma-luego de señalar que los compromisos económicos del Estado deben contar con registro presupuestal (...) La sanción por la violación a esta norma es clara: el funcionario que omita el requisito responde disciplinaria, penal y fiscalmente, incluso patrimonialmente-alcance personal de la conducta-, por ejecutar un contrato sin respaldo presupuestal ${ }_{;}$pero de allí no se desprende que cualquier vicio asociado a este requisito-exigible a todos los actos o contratos que involucren gastos-se sancione con nulidad. Un entendimiento amplio o extendido de las consecuencias derivadas de los defectos de este requisito produciría, inclusive, la nulidad un acto administrativo de contenido laboral que reconozca un pago sin tener el registro presupuestal de respaldo. Semejante alcance es inaceptable, porque es claro que la validez del acto y la responsabilidad del funcionario que lo expide sin cumplir esta obligación son aspectos diferentes. (...) la Sala confirma y consolida (...) que la ausencia de disponibilidad y con mayor de registro presupuestal no producen ni inexistencia ni nulidad del contrato estatal. Nota de Relatoria: Al respecto consultar Consejo de Estado, Sección Segunda, sentencias de 11 de marzo de 2010, exp. 0792-06 y de 22 de abril de 2010, exp. 2611-07. Sección Tercera, sentencias de 23 de junio de 2005, exp. 12846 y de 16 de agosto de 2012, exp. 24463 fuente formal: decreto 111 de 1996-articulo 71. 


\section{ANÁLISIS DE LA JURISPRUDENCIA SOBRE EL USO DEL \\ TITULO VALOR Y EN ESPECIAL EL "CHEQUE" POR PARTE \\ DE LA ADMINISTRACIÓN PÚBLICA EN COLOMBIA}

Según la doctrina "Los títulos valores dentro de la contratación estatal, son perfectamente aplicables para respaldar las distintas obligaciones contractuales adquiridas tanto por la administración, como por los propios contratistas, siempre y cuando los títulos se deriven de contratos estatales" 19 .

Teniendo en cuenta lo dicho por el Consejo de Estado, en relación a que la única fuente generadora de títulos valores en la administración pública, es un contrato estatal, resulta lógico pensar que, para poder iniciar la ejecución, se requiere de un título complejo, en donde además del título, se allegue el contrato que dio origen al título.

Sin embargo; al estudiar la jurisprudencia, se encuentran verdaderas dudas y/o posibilidades acerca de la existencia de un título valor emitido por parte de la administración pública sin contrato previo, pues al estudiar la tesis expuesta en el auto 21 de febrero de 2002, expediente 19270 C.P. Alier Hernández Enriquez, Sección Tercera Consejo de Estado, en donde se concluyó que:

La jurisdicción contenciosa es la competente siempre que se cumplan los siguientes requisitos:

1. Que el título valor haya tenido la causa en el contrato estatal ${ }^{20}$, que respalde obligaciones derivadas del contrato.

2. Que el contrato del cual surgió el título valor sea de aquellos de los cuales conoce la jurisdicción contenciosa administrativa

3. Que las partes del título valor sean las mismas del contrato estatal.

4. Que las excepciones derivadas del contrato estatal sean oponibles en el proceso ejecutivo.

En virtud de la anterior postura jurisprudencial, surge un gran enigma: ¿Cuáles son los casos en que los títulos valores que emanan de la administración pública, no tienen su causa en un contrato estatal?, y de los cuales se ha reservado su conocimiento en exclusiva al juez ordinario civil.

La respuesta a este interrogante sería de gran ayuda para evitar la problemática que hoy se ventila en la mayoría de despachos judiciales, en donde el

19 La acción ejecutiva ante la jurisdicción administrativa, MAURICIO FERNANDO RODRÍGUEZ TAMAYO 5 edición, librería jurídica Sánchez R Ltda., p. 114. De tal forma, que si el contrato estatal del que se deriva el titulo valor, se declara nulo, la jurisdicción administrativa, carece de competencia para conocer de esa ejecución porque siempre se requiere de la presencia del contrato estatal. Ver Consejo de Estado, sección tercera, subsección A, sala unitaria, auto de 12 de mayo de 2015, expediente 51230, CP Hernán Andrade Rincón.

Subrayado de la autora. 
Juez está esposado para hacer un adecuado control de legalidad, debido a que bajo el principio mercantil de "autonomía" del título valor, basta con que este sea presentado, para que se deba librar el mandamiento de pago, siempre y cuando se cumplan los requisitos generales y especiales del título establecido en el código de comercio u otras normas.

A vía de ejemplo, y para reafirmar el tema en estudio, se trae a colación la postura del Honorable Tribunal Superior de Distrito Judicial de Cartagena-Sala Civil, quien, frente a este polémico tema, ha dicho lo siguiente:

"Si la ejecución se promueve con un título valor, la competencia es de la jurisdicción ordinaria civil, con abstracción si el título fue librado por el Estado, en cuyo caso el título tiene vocación suficiente para servir de título ejecutivo, no siendo imperativo adosar otros documentos, entre ellos, el negocio causal (...)

"En conclusión, estando frente a cheques que son verdaderos títulos valores, se ejercita la acción cambiaria que es propia del derecho mercantil, en consecuencia el título por si solo presta mérito ejecutivo $(\ldots)^{\prime \prime 21}$.

Conforme a este enfoque, el juez civil no puede ni siquiera indagar si a la ejecución que se le está presentando le precede o no, un determinado contrato estatal, no solo para poder definir la jurisdicción competente; sino que, además, le permita ser garante de la protección del patrimonio público.

Aunado a lo anterior, el juez civil tampoco podrá decretar la caducidad, ni admitir ninguna excepción frente al negocio o contrato que le da origen al título, ya que comoquiera que uno de los requisitos para que conozca la jurisdicción contenciosa administrativa es que las excepciones derivadas del contrato estatal sean oponibles en el proceso ejecutivo; se tiene que de acuerdo al enfoque planteado por algunos Tribunales, en este tipo de ejecuciones no se puede exigir la conformación de un título complejo, en virtud de la autonomía del cheque, primando este principio de derecho mercantil, frente a otros principios constitucionales.

Como corolario de lo anterior, el juez ordinario en su especialidad civil, no está dotado de los poderes que ostenta el juez de lo contencioso administrativo, y por ende no gozan de mecanismos para protección del patrimonio público cuando la administración no ha ejercitado su defensa, distintos a la vinculación del Ministerio Público, o a la Agencia Nacional de Defensa Jurídica del Estado, quienes en algunos de los casos ni siquiera acuden al 1lamado 22 .

21 Apelación auto, magistrado ponente Marcos Román Guio Fonseca, radicado 134303103001201600103-01, Tribunal 2017-296-23. Tribunal de Cartagena sala civil.

22 Transparencia en la contratación-Es tarea del juez de la acción popular garantizar la moralización de los procesos de contratación, más allá del principio de legalidad / acción popular-Mecanismo principal e idóneo para la defensa de los derechos colectivos, no 
Así las cosas, se plantea el siguiente interrogante ¿Puede la Administración pública emitir títulos valores sin que estén precedidos de un contrato estatal? y $\operatorname{Sin}$ que estén respaldados en un registro presupuestal y sin certificado de disponibilidad presupuestal?, ¿Puede la Administración pública emitir títulos valores, sin que estén comprendidos dentro de la legalidad del gasto público?

La jurisprudencia de la sala disciplinaria del Consejo Superior de la Judicatura, pareciera tener en cuenta dos tesis respecto a los títulos valores, a saber: Teoría de la abstracción y teoría de la causalidad.

"En cambio, respecto de la letra de cambio y el pagaré -que son algunos de los títulos abstractos, es decir de aquellos cuya relación con el contrato causal pierde importancia-bay quienes sostienen que el derecho incorporado en el título, siempre, sin excepción, se rige por los principios y normas del derecho cambiario y que, por eso, no importa lo que suceda con el contrato subyacente.

Otros, en cambio, sobre todo los causalistas, opinan que tal aserto no se cumple en todos los eventos, pues el título sólo cobra independencia absoluta del negocio causal cuando efectivamente ba circulado. Los defensores de la teoría absoluta de la abstracción arguyen que la circulación del título no cambia su naturaleza abstracta, pues el deudor que entrega una letra de cambio o un pagaré, no lo bace con el propósito de que éste circule, sino que por el contrario tiene en consideración unica y exclusivamente que se compromete a pagar a su acreedor... incondicionalmente una suma determinada, en fecha precisa y con el rigor cambiario ${ }^{23}$.

"La tesis que ba venido sosteniendo la Sala debe revisarse en cuanto se ba formulado con alcances absolutos, pues la sola existencia de títulos valores de contenido crediticio no siempre bace que la relación entre sus partes se rija por el derecho cambiario. En efecto, cuando el título permanece entre las partes del negocio subyacente conserva relevancia la relación causal entre éste, por lo cual, el deudor puede oponer excepciones propias del contrato y el juez deberá aplicar el derecho que lo rige.

De acuerdo con lo dicho, cuando se trata de contratos estatales que originaron la creación de un título valor, por ejemplo, de un pagaré, que no ba circulado y cuyo cobro se pretende por la vía judicial, teniendo en cuenta que se pueden oponer excepciones propias del contrato estatal, el competente para conocer de la ejecución será el juez de lo contencioso administrativo, siempre que concurran los siguientes requisitos: -Que el título valor haya tenido como causa un contrato estatal. -Que el contrato del que se trate sea de aquellos de los que conoce la jurisdicción contenciosa administrativa.

supeditado a la existencia de otros medios ordinarios / violación o amenaza de derechos colectivos-Permite al juez declarar la nulidad absoluta del contrato / defensa de los derechos colectivos-Se exige tanto en la etapa precontractual, como en la etapa contractual (celebración, ejecución y liquidación de los contratos). Consejo de Estado, sala de lo contencioso administrativo, sección tercera, Consejera ponente: Stella Conto Díaz del castillo, dos (2) de diciembre de dos mil trece (2013), Radicación n. ${ }^{\circ}$ 76001-23-31-000-2005-02130-01(AP).

23 Teoría de la abstracción y teoría de la causalidad en los títulos valores-Aplicación en el Código de Comercio Colombiano / Nota de Relatoría: Ver sentencia de la Corte Suprema de Justicia, Sala de Casación Civil del 19 de abril de 1993. 
-Que las partes del título lo sean también del contrato. -Que las excepciones derivadas del contrato sean oponibles en el proceso ejecutivo" 24 .

En la anterior jurisprudencia se dirimió un conflicto de competencia, pero sobre el título valor - facturas, sin embargo, para esta investigación vale la pena analizar las argumentaciones allí contenidas frente al uso de cualquier título valor por parte de la administración, pues allí se dijo:

"Aclarada de esta manera la naturaleza del documento - factura cambiaria-y analizada la normatividad anterior y los documentos allegados al plenario y base de la ejecución, nos encontramos con que éstos contienen los requisitos que exige la ley para que sean títulos valores. Asílas cosas, al tratarse de facturas cambiarias de compraventa, esta Sala Disciplinaria se ba pronunciado en el sentido de adscribir la competencia a la justicia ordinaria, por ser dicho título valor un documento necesario para legitimar el ejercicio del derecho literal y autónomo que en él se incorpora, tal y como lo preceptúa el artículo 619 del Código de Comercio. ${ }^{25}$ Pese a lo anterior, se hace necesario esta vez rectificar parcialmente el criterio jurisprudencial anterior, para acoger la tesis esbozada por la Sección Tercera del Consejo de Estado. En efecto, para dicha Corporación, los jueces administrativos tendrán competencia para conocer de acciones ejecutivas derivadas de títulos valores, siempre que éstos cumplan con las siguientes condiciones, a saber:

i) Que el título valor baya tenido su causa en el contrato estatal, es decir, que respalde obligaciones derivadas del contrato; ii) que el contrato del cual surgió el título valor sea de aquellos de los cuales conoce la Jurisdicción Contencioso Administrativa, iii) que las partes del título valor sean las mismas del contrato estatal y iv) que las excepciones derivadas del contrato estatal sean oponibles en el proceso ejecutivo.

El criterio jurisprudencial anterior, también, es compartido por el doctor Mauricio Rodríguez Tamayo ${ }^{10}$, cuando al respecto, sostiene: "Por el contrario, se cree que, si el título valor tiene su fuente en un contrato estatal y se dan las condiciones fijadas por la jurisprudencia del Consejo de Estado, el asunto, necesariamente, deberá ser conocido por la justicia administrativa, pues cobra plena aplicación la previsión clara y especial del artículo 75 de la ley 80 de 1993".

Luego entonces, la jurisprudencia ha ido dejando entrever, con poca profundidad, que la contratación estatal no es posible asimilarla a la contratación mercantil ${ }^{26}$, en lo que atañe a algunos aspectos como la formalidad y reglamen-

24 Consejo Superior de la Judicatura Sala Jurisdiccional Disciplinaria, Diez (10) de diciembre de dos mil doce (2012), Radicado: 110010102000201202768 00, Magistrado Ponente: Dr. Henry Villarraga Oliveros.

25 Conflicto jurisdicción radicación 1100101020082545 , auto de octubre 16 2008, Sala 100.- M.P. Dra. Julia Emma Garzón de Gómez

26 (...)Las divergencias que surjan entre las partes en relación con los actos administrativos que dicta la administración con ocasión de la celebración, el desarrollo, la terminación y la liquidación del contrato, teniendo en cuenta que si bien el Estado en materia contractual 
tación de la misma, ya que en materia mercantil prima la agilidad del comercio y por lo tanto la consensualidad de las transacciones, en contratación estatal siempre prima la formalidad, lo que conlleva a una poca celeridad, salvo en casos excepcionales como la urgencia manifiesta.

Así las cosas, por vía jurisprudencial se definió cuando debía conocer de cierto tipo de litigios el juez ordinario, y cuando el juez de lo contencioso administrativo, dejando bien en claro la necesidad de buscar la fuente ${ }^{27}$, que no es otra cosa que el contrato estatal ${ }_{i}$ en virtud de la formalidad como característica de la contratación estatal (Reglada), la cual se vuelve imposible delimitar aplicando el principio de "autonomía y literalidad del título valor", por parte de los jueces civiles.

En conclusión, aunque es frecuente hoy en día que la administración pública pueda utilizar títulos valores (Cheque), existen límites y responsabilidades, para ese emisor ${ }^{28}$, siendo la primera restricción la existencia de un contrato estatal ${ }^{29}$, así como la aplicación de los principios de legalidad del gasto público; y aunque el cheque sea un medio de pago, no es menos cierto que en la administración pública todo pago está supeditado a la disponibilidad dentro de un presupuesto y a la destinación específica de los recursos, razones por las que urge gestar una legislación que prevea este tipo de situaciones, en aras de poderle dar una adecuada y temprana protección al patrimonio público por ser un pilar fundamental en el Estado Social de Derecho.

se rige por los principios de la contratación entre particulares, con preeminencia de la autonomía de la voluntad y la igualdad entre las partes contratantes, también se rige por disposiciones extrañas a la contratación particular, las cuales buscan la conservación y prevalencia del interés general, como la satisfacción de las necesidades de la comunidad implícitas en los contratos estatales. Al respecto, ha dicho la doctrina que: Las diferencia entre unos y otros, en este aspecto [refiriéndose a los contratos celebrados por los particulares y entre éstos y el Estado] reside que en que mientras las convenciones hechas en un contrato de derecho privado son inmutables y sus términos inflexibles, las que conforman el contrato administrativo no gozan de esa inmutabilidad e inflexibilidad rigurosa, sino que admiten cierto grado de mutabilidad cuando lo impone el interés público que constituye la finalidad del contrato, mutabilidad que queda restringida a límites reducidos ya que lo estipulado por las partes en el contrato administrativo debe respetarse en su esencia, de modo tal que no resulten alterados el objeto y el contenido de la convención". (ESCOLA, HÉCTOR JORGE, Tratado Integral de los Contratos Administrativos).

27 Subrayado de la autora.

28 Necesariamente es un empleado público (Partiendo de la base que las cuentas corrientes de entidades públicas puede ser aperturadas por personal con cargos directivos)

29 Los títulos valores siempre tienen como origen un "negocio causal", ya sea oneroso o gratuito; por ende, ya sea que se trate de un contrato de prestación de servicios, un contrato laboral o de otra índole, en donde el contratante sea la administración pública, sería absolutamente necesaria la existencia de un contrato, para que se emita el respectivo título valor. 


\section{CONCLUSIONES}

De acuerdo al estudio anterior se sella la importancia de comprender el frecuente uso por parte de la administración pública del título valor - cheque, y la necesidad de legislar sobre él, cuándo esta es, quien lo suscribe.

Ante las situaciones problemáticas citadas, es importante armonizar las relaciones mercantiles y de derecho público, haciendo un estudio sistemático de las normas posteriores y especiales relacionadas con el tema, bajo el entendido que el código de comercio $^{30}$ es anterior a la Constitución de 1991, al estatuto de contratación estatal (Ley 80 de 1993), a la Ley 1437 de 2011 CPACA, y al decreto 111 de $1996^{31}$, y por ser estas normas posteriores y de carácter especial en materia de derecho público, prevalece su aplicación.

Con el advenimiento del Estado Social de derecho, sobrevienen algunos principios como el de legalidad del gasto público ${ }^{32}$, y la contratación estatal reglada ${ }^{33}$ que son de imperativo cumplimiento, para todas las autoridades administrativas y jueces de la república, sin embargo; en lo que atañe al juez ordinario en la especialidad civil, se encuentra desprovisto de poderes que le permitan proteger el patrimonio público, por lo que se propone una adecuada técnica jurídica del legislador para abordar el uso del cheque por parte de las entidades públicas, basada en la experiencia de la cuestión litigiosa recibida a diario, por los Tribunales Superiores de Distritos judiciales, así como por parte de los juzgados.

Todo lo anterior con el único fin de hacer un uso adecuado de los cheques por la administración pública, e imponerle al suscriptor límites.

Por último, la jurisprudencia a pesar de sus esfuerzos, también ha dejado los siguientes interrogantes:

- Si es la jurisdicción ordinaria en su especialidad civil, la competente para conocer de este tipo de acciones en donde hay endoso del título valor (Cheque), ¿Cómo lograr una protección por parte del Juez, en relación al patrimonio público, cuando la administración no ejerce su defensa?,

- Si al momento de endosar el título valor se pierde el carácter de título complejo, o es que definitivamente clos títulos valores (Cheques) emitidos por la Administración Pública, nunca han tenido el carácter de complejos?

30 Expedido el día 27 de marzo de 1971

31 Estatuto Orgánico del presupuesto.

32 Sentencia C-772 de 1998, Corte Constitucional. M.P. Fabio Morón Díaz.

33 Artículos 1, 2, 58, 333, 365 Constitución Política de 1991. Ley 80 del 93 artículo 13. De la normatividad aplicable a los contratos estatales. Los contratos que celebren las entidades a que se refiere el artículo 2o. del presente estatuto se regirán por las disposiciones comerciales y civiles pertinentes, salvo en las materias particularmente reguladas en esta ley. 
- Cuando el título valor es endosado, que sucede con las irregularidades frente al negocio causal o excepciones derivadas del contrato, la administración pública se queda sin defensa? ${ }^{34}$.

- ¿Cómo podría ejercer su defensa la administración pública aduciendo frente al juez ordinario en su especialidad civil, principios ajenos a los títulos valores, como son moralidad y legalidad del gasto público, y contratación reglada, si para el juez ordinario civil solo le es usual el principio de autonomía y literalidad del título valor?

\section{BIBLIOGRAFÍA}

GUILLERMO VÁSQUEZ MÉNDEZ- editorial jurídica de Chile- tratado sobre el chequehistoria- legislación- doctrina y jurisprudencia.,

https://ciberconta.unizar.es/leccion/der021/100.HTM

http://rosauft.blogspot.com/2015/04/titulos-valores.html

Consejo de Estado, Sección Tercera, Subsección A, sala unitaria, auto del 12 de mayo de 2015, expediente 51230. C.P Hernán Andrade Rincón.

Código de comercio Decreto 130 de 1976, Libro Tercero.

Estatuto Orgánico del presupuesto.

Revista Prolegómenos de la Universidad Militar de la Nueva Granada, volumen 9, número 17, enero-junio 2006, pp. 23 y 24. ISSN 0121-182X.

Sentencia c-154 de 1997, Corte Constitucional.

ROMÁN GUIO FOnSECA MARCOS, Los títulos valores, análisis jurisprudencial, ediciones doctrina y ley.

Ley $1^{\circ}$ de 1980 .

Ley 80 de 1993.

Biblioteca jurídica virtual del instituto de investigaciones jurídicas de la UNAM. www. Juridicas.unam.mx.

34 El decreto 111, art. 71 dice que es el empleado el que responde de forma personal, "cualquier compromiso que se adquiera con violación de estos preceptos creará responsabilidad personal y pecuniaria a cargo de quien asuma estas obligaciones" Ley 33 de 1989 artículo 86, Ley 179 de 1994 articulo 49. 
Constitución Política de 1991

C -713 de 2009 Corte Constitucional

Mauricio Fernando Rodríguez Tamayo, La acción ejecutiva ante la jurisdicción administrativa, $5^{\text {a }}$ edición.

Decreto 111 de 1996

Observatorio colombiano de contratación pública. http://occp.co

Consejo de Estado Sala de lo Contencioso Administrativo Sección Tercera Subsección C Consejero ponente: Enrique Gil Botero Bogotá D.C., doce (12) de agosto de dos mil catorce (2014) Radicación n. ${ }^{\circ}$ 05001-23-31-000-1998-01350-01(28565).

Consejo de Estado, Sección Segunda, sentencias de 11 de marzo de 2010, exp. 0792 06 y de 22 de abril de 2010, exp. 2611-07. Sección Tercera, sentencias de 23 de junio de 2005, exp. 12846 y de 16 de agosto de 2012, exp. 24463.

Auto 21 de febrero de 2002, expediente 19270 C.P. Alier Hernández Enríquez, Sección Tercera Consejo de Estado.

Consejo de Estado, sección tercera, subsección A, sala unitaria, auto de 12 de mayo de 2015, expediente 51230, CP Hernán Andrade Rincón.

Consejo de Estado, sala de lo contencioso administrativo, sección tercera, Consejera ponente: Stella Conto Díaz del castillo, dos (2) de diciembre de dos mil trece (2013), Radicación n. ${ }^{\circ}$ 76001-23-31-000-2005-02130-01(AP).

Sentencia C-1436 de 2000 Corte Constitucional.

Consejo Superior de la Judicatura Sala Jurisdiccional Disciplinaria, Diez (10) de diciembre de dos mil doce (2012), Radicado: 110010102000201202768 00, Magistrado Ponente: Dr. Henry Villarraga Oliveros.

Conflicto jurisdicción radicación 1100101020082545 , auto de octubre 16 2008, Sala 100.- M.P. Dra. Julia Emma Garzón de Gómez.

Sentencia C-772 de 1998, Corte Constitucional. M.P. Fabio Morón Díaz. 